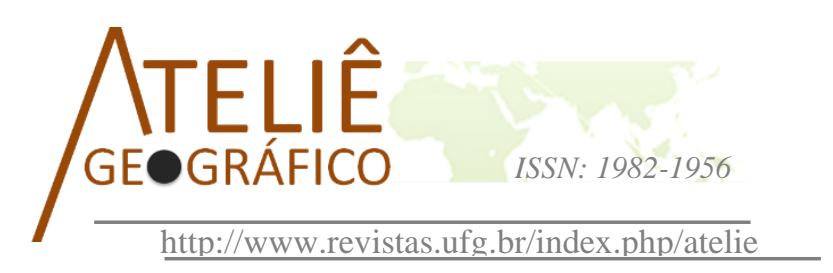

\title{
Diálogos entre Geografia e Ciências Sociais: Região, Regionalidade e América Latina e Caribe
}

\author{
Diálogos entre Geografía y Ciencias Sociales: Región, \\ Regionalidad y América Latina y el Caribe
}

\section{Dialogues between Geography and Social Sciences: Region, Regionality and Latin America and the Caribbean}

\author{
Adalberto de Salles-Lima \\ Universidade de Brasília \\ sallesvitoria@hotmail.com
}

\begin{abstract}
Resumo
O presente artigo propõe desenvolver uma reflexão crítica a partir da Geografia e das Ciências Sociais Latino-Americanas, acerca da relação entre dinâmicas regionais e as categorias de análise geográfica e regional América Latina e Caribe. O objetivo é analisar a possível insuficiência do universalismo europeu sobre as nomenclaturas América Latina e Caribe frente a particularidades culturais, territoriais e processos sociais contra-hegemônicos. O método qualitativo norteará a metodologia baseada na interpretação de materiais bibliográficos clássicos e contemporâneos para analisar outras alternativas de regionalização deslocadas do essencialismo econômico, colonial e imperialista da cartografia tradicional. Acreditamos em outras linguagens possíveis de distintas cartografias conforme diferentes regionalizações do continente, baseados em aspectos históricos, críticas teóricas, fluxos migratórios, populações étnico-raciais, distribuição sócioespacial de grupos econômicos e aspectos políticoideológicos.
\end{abstract}

Palavras-chave: Geografia, Ciências Sociais, Região, América Latina.

\section{Resumen}

El presente artículo propone desarrollar una reflexión crítica a partir de la Geografía y de las Ciencias Sociales Latinoamericanas, acerca de la relación entre dinámicas regionales y las categorías América Latina y el Caribe. El objetivo es analizar la posible insuficiencia del universalismo europeo sobre las nomenclaturas América Latina y el Caribe frente a las particularidades culturales, territoriales y procesos sociales contrahegemónicos. El método cualitativo orientará la metodología basada en la interpretación de materiales bibliográficos clásicos y contemporáneos para analizar otras alternativas de regionalización desplazadas del esencialismo económico, colonial e imperialista de la cartografía tradicional. Creemos en otros lenguajes posibles de distintas cartografías según diferentes regionalizaciones del continente, basadas en aspectos históricos, críticas teóricas, flujos migratorios, 
poblaciones étnico-raciales, distribución socioespacial de grupos económicos y aspectos político-ideológicos.

Palabras clave: Geografía, Ciencias Sociales, Región, América Latina.

\begin{abstract}
This article proposes to develop a critical reflection based on Latin American Geography and the Social Sciences, about the relationship between regional dynamics and the categories Latin America and the Caribbean. The objective is to analyze the possible insufficiency of European universalism on the Latin American and Caribbean nomenclatures in the face of cultural and territorial specificities and counter-hegemonic social processes. The qualitative method will guide the methodology, based on the interpretation of classic and contemporary bibliographic materials to analyze other alternatives of regionalization displaced from the economic, colonial and imperialist essentialism of traditional cartography. We believe in other possible languages of different cartographies according to different regions of the continent, based on historical aspects, theoretical critiques, migratory flows, ethnic-racial populations, socio-spatial distribution of economic groups and political-ideological aspects.
\end{abstract}

Keywords: Geography, Social Sciences, Region, Latin American.

\title{
Introdução
}

O debate sobre região e regionalismo em cada área do conhecimento científico possui sua própria linguagem, uma abordagem eminentemente interdisciplinar (CLAVAL, 1987). A escala pode ser considerada um elemento analítico estrutural na interpretação da região e suas espacialidades territoriais, presente entre as áreas científicas das ciências humanas. Na condição de geógrafo e cientista social é desafiador desenvolver um diálogo entre essas referidas ciências a partir das categorias evidenciadas aqui.

Em linhas gerais, as abordagens macro voltadas para Região e Regionalismo na América Latina e Caribe associam-se ao campo geopolítico e histórico de dominação econômica, científica, tecnológica e cultural do Norte (Estados Unidos e Europa) sobre as periferias meridionais do sistema capitalista. Algumas representações espaciais das Américas são mais difundidas por estarem associadas aos aspectos do capitalismo moderno e físico do território, sendo eles: América Latina, América do Norte, América Central, América do Sul e América Anglo-Saxão.

Esses recortes são vistos nas cartografias tradicionais, influenciam nas construções das identidades dos sujeitos, nos imaginários sociais e projetos nacionalistas. Parte dessa construção social é fomentado no ensino fundamental e médio. A geografia escolar reproduz parcialmente a cartografia tradicional ao apresentar essas categorias como metodologias de análises da regionalização do espaço mundial. É responsável em grande parte por construir noções regionais e a aplicação das categorias para amplo uso na sociedade atual.

O presente artigo propõe refletir acerca do conceito Gran Caribe a partir da crítica de América Latina para compreender outras possíveis leituras de regionalização 
no continente. O desafio é pensar o continente sob outras lógicas de regionalização críticas à leitura geopolítica eurocêntrica na determinação dos territórios de modo físicoeconômico na conformação das contradições espaciais sistêmicas: Norte-Sul, CentroPeriferia, Latina-Anglo-Saxão e muitas vezes reproduzidas por instituições de pesquisas governamentais e independentes.

A crítica latino-americana com base nas ciências sociais e na geografia mostra que a natureza eurocêntrica desses termos cria uma identidade regional subjugada a lógica das dinâmicas do capitalismo moderno/colonial. No campo das contradições culturais-materiais estrategicamente propositais, ser oriundo de uma periferia do sul global é estar condicionado a uma cidadania não pertencente da potência mundial imperialista, atualmente os Estados Unidos e, nem pertencer a uma identidade regional colonialista e hegemônica, a Europa. Nesse aparente limbo geopolítico, estão os países e regiões periféricas do mundo.

$\mathrm{O}$ artigo está dividido em quatro momentos. No primeiro, Categoria, Região $e$ Regionalidade, apresenta perspectivas teóricas clássicas e contemporâneas de Região e Regionalização a partir da Geografia. No segundo, Modernidade e Colonialidade na América Latina, reflete a América Latina e o Caribe como invenções da modernidade na ampliação do capitalismo colonial/moderno.

No terceiro, Perspectiva Crítica e desprovincialização do pensamento, discute as contribuições da Teoria da Dependência na análise do (sub)desenvolvimento latinoamericano, surgimento de alguns blocos político-econômicos regional e críticas das Ciências Sociais local na interpretação da realidade latino-americana. No último subitem, Olhares sobre as Américas e o Gran Caribe, alguns aspectos históricos fundantes das Américas e a necessidade de repensar o termo Caribe a partir de outra regionalização, com proposta de aplicação da categoria Gran Caribe.

\section{Categoria, Região e Regionalidade}

Entende-se por "categoria" o recurso teórico-metodológico utilizado para buscar um olhar mais objetivo e essencialista de uma realidade. Os propósitos científicos das categorias para o conhecimento estão ligados à resolução dos problemas da correlação entre o particular e o geral na realidade objetiva e na consciência, na busca pelas origens das evidencias, suas essências e diálogo com as formações materiais das realidades concretas (CHEPTULIN, 1982). Cada categoria explica um contexto social e como este estabelece relação com a totalidade.

Quando categorizamos um determinado espaço geográfico, a exemplo de América Latina, estamos mergulhando em perspectivas teóricas e metodológicas muitas vezes despercebidas ou mesmo por escolha científica. O que entendemos por América Latina? Quais as possibilidades de uso desse termo? Enquanto categoria regional inclinase mais para uma análise universalista ou particularista? Há outras possibilidades de 
regionalização desse continente? Tentaremos refletir sobre essas e outras questões, começando com uma breve análise conceitual de região.

Região é um dos conceitos estruturais da Geografia para entender parte das dinâmicas dos territórios, sociedades e desde o século XVIII vem passando por transformações conceituais. Até meados desse século, não haviam sido consolidados estudos com rigor científico sobre regionalização preocupados numa melhor sistematização das áreas, buscando propor formas de classificação, técnicas de análises e melhor descrições das partes terrestres. O que se tinha eram buscas por identificação das especificidades e curiosidades em cada parte do globo (CLAVAL, 1974).

Já no início do século XX começou a surgir uma "Geografia Regional" originada na Europa e nos Estados Unidos, como propulsores das primeiras definições do fenômeno regional os teóricos Vidal de la Blache, e A. J. Herbertson (DUARTE, 1980). A. J. Herbertson elaborou a primeira definição sistematizada da noção de região ao destacar uma "geografia sistemática" e com "ordens de divisões geográficas [...]" no globo terrestre. (HERBERTSON, 1905, p.301). O autor teve a influência da biologia para propor uma divisão do mundo em grandes regiões naturais.

Vidal de la Blache foi um dos fundadores da Escola Regional Francesa e buscou relacional os aspectos "naturais" e "humanos" em suas análises para explicar os fenômenos geográficos, seguindo um caminho distinto de Gallois em sua definição de "região natural" orientado pelos aspectos físicos, conforme o clima, altitude e constituição geológica do solo. Vidal propôs o conceito de "gênero de vida"1 como síntese da relação entre as disponibilidades físiográficas de cada lugar e as dinâmicas de adaptações de cada sociedade. Nesse sentido, Vidal defendia as ações humanas como agentes transformadores do meio, onde as dinâmicas da relação homem-meio deveriam ser situadas nas próprias condições locais.

A análise das relações entre o homem e o meio a partir do ângulo espacial $\left(\right.$ SORRE, 2003) ${ }^{2}$ é um dos fundamentos da Geografia Humana. No século XX, as críticas realizadas a esse campo científico foram mais acentuadas por conta das recentes transformações das sociedades e do capitalismo. Desde o seu início, a região era definida pelas condições territoriais naturais, independentemente das intervenções humanas. Aos poucos, a noção deste como um produto da relação entre o meio e o homem e depois como construção social definido pelo homem conforme seus próprios critérios foram se consolidando na comunidade científica. Dito isso, é a superação do predomínio da "região natural" para "região geográfica".

$\mathrm{Na}$ crítica aos fundamentos da região como um dado natural e histórico, Lacoste (1989) acredita ser politicamente mais adequado considerá-la como uma forma espacial de organização política. Consoante esse pensamento, Santos (1991) propôs a superação da perspectiva de la Blache das condições locais de homem-meio na definição de região,

${ }^{1} \mathrm{O}$ autor escreveu "Os Gêneros de vida na Geografia Humana" (Les genres de vie dans la Géographie Humaine - premier article) em 1911, publicado em Annales de Géoographie, n 111, ano XX, tomo 20.

${ }^{2}$ Traduzido de El Hombre en la Tierra, Introducción, 1967. 
uma vez que os progressos no domínio dos transportes e das comunicações, assim como a expansão propositalmente desigual da economia internacional explicam a crise da noção clássica. De acordo com o autor, "nas condições atuais da economia universal, a região já não é uma realidade viva, dotada de coerência interna. Definida sobretudo do exterior, seus limites mudam em função dos critérios que lhe fixamos. Por conseguinte, a região não existe por si mesma" (p.9-10).

No campo teórico, Santos (1985) afirma a região ser “[...] o lócus de determinadas funções da sociedade total em um momento dado" (p. 66) e definida "[...] como o resultado das possibilidades ligadas a uma certa presença nela, de capitais fixos exercendo determinado papel ou determinadas funções técnicas e das condições do seu funcionamento econômico" (p.67). As regionalizações com base nos pressupostos da tradição francesa de "paisagem" e "gênero de vida" já não são suficientes para compreender as dinâmicas regionais globais, em especial a região latino-americana, uma vez que os fenômenos que incidem sobre esses territórios não são exclusivamente internos.

Haesbaert (2010) define o fenômeno como entidade geográfica. Ela é, antes de tudo, um processo de regionalização, seja como procedimento metodológico ou instrumento de análise proposto pelo pesquisador, seja a partir das dinâmicas espaçotemporais efetivamente vividas e produzidas pelos grupos sociais. Portanto, a análise regional deve considerar o campo da produção material/funcional (o político-econômico com rebatimentos no material-“natural”) e das representações simbólicas (o simbólicocultural). Nesse sentido, na condição de entidade geográfica é expressão da interação entre a produção material e o campo subjetivo do simbólico e cultural. A região é uma categoria de análise política e ao mesmo tempo racional pela sua natureza funcional.

Ao considerarmos a região nas perspectivas de Lacoste (1989) como organização espacial política, em Santos $(1985,1991)$ como lócus de determinadas funções da sociedade e do capital e por Haesbaert (2010) enquanto entidade geográfica, esse fenômeno social através da relação material e simbólica evidencia uma natureza político-cultural e racional. É político-cultural no sentido de ser uma ferramenta espacial criadora de novas regionalizações. A participação dos Estados-Nações e acontecimentos de processos históricos por grupos sociais seriam agentes fundamentais na formação de novas regionalidades. Consoante essa compreensão, seria "[...] um espaço que é o produto da história e da cultura" (LENCIONI, 2003 p.154).

É racional por possuir uma funcionalidade econômica, necessária para a manutenção da estrutura econômica moderna, basicamente através da dicotomia entre centros/ centralidades e periferias. Nos dois âmbitos de análise, o fenômeno como construção social é ordenador de territórios. Na Corrente Crítica, a região é analisada como uma dimensão espacial do processo desigual e combinado do capitalismo (CORRÊA, 2003).

A regionalização em Haesbaert (2010) é vista como processo de diferenciação e/ou de recorte do espaço em parcelas coesas ou articuladas de estar articulada na ação 
dos sujeitos e na interação produzida por eles. Tal articulação deve ser entendida "em seu sentido relacional, totalmente impregnado nas dinâmicas de produção da sociedade (p. 6)". Portanto, a regionalidade para o autor é um produto das dinâmicas da produção da sociedade ao evidenciar seu conteúdo como superação da forma espacial ao ressignifiiar as transformações e ações dos sujeitos e processos sociais, políticos e culturais, uma "propriedade do 'ser' regional" (p.4).

Por fim, a perspectiva de regionalidade em Haesbaert está afinado com o entendimento acerca de processos históricos em curso da produção do espaço latinoamericano pela modernidade. A superação da forma espacial como elemento essencialista decorre do conteúdo produzido pelas dinâmicas das sociedades e suas contradições.

\section{Modernidade e Colonialidade na América Latina}

A modernidade criou a região americana como uma instância racional do território, para cumprir uma função econômica-material no capital moderno/colonial. As contribuições do Estruturalismo Latino-Americano e da Teoria da Dependência ${ }^{3}$, através do método histórico-estruturalista para pensar o (sub)desenvolvimento e industrialização na América Latina possibilitou analisar a oposição entre centro e periferia, entendendo a estrutura econômica mundial determinar um padrão específico de inserção dos países latino-americanos na condição de periferia. O pensamento da Comissão Econômica para a América Latina e Caribe (CEPAL) contribui para entender que a América Latina ainda não vivenciou profundas rupturas em sua estrutura econômica imposta pela modernidade.

A estrutura socioeconômica do continente latino-americano implicaria num modo singular de industrialização, progresso técnico, crescimento e absorção da força de trabalho. As análises apontaram o subdesenvolvimento regional não significar uma "etapa" de um processo universal de desenvolvimento, mas, um fenômeno próprio e singular, distinto do que ocorre nas economias centrais, por conta de uma estrutura pouco diversificada e tecnologicamente heterogênea (BIELSCHOWSKY, 2000).

As últimas décadas mostraram que o aumento da produção em grande escala provocada pelo progresso tecnológico e científico associado ao aumento do consumo não impediu o agravamento das desigualdades sociais. A produção capitalista do espaço é propositalmente diferenciada, sobretudo em termos de desenvolvimento e de distribuição de estruturas materiais (SANTOS, 2004; HARVEY, 2005). O liberalismo desenvolvido essencialmente no centro teve que se ajustar ao apropriar-se das periferias, adaptando-se as condições sociais e de produção. Isso porque a

\footnotetext{
3 A teoria da Dependência foi desenvolvida por alguns intelectuais americanos como Vania Bambirra, Theotonio dos Santos, Ruy Mauro Marini e André Gunder Frank, baseado em uma leitura crítica e marxista não-dogmática dos processos de reprodução do subdesenvolvimento na periferia do sistema internacional, entre as décadas de 1960 e 1970.
} 
centralidade do capital-industrial no mundo não prevê a homogeneização completa do espaço, por não ser compatível com o capitalismo (CORRÊA, 1995).

Ampliaram-se as fronteiras para o fluxo desigual do capital e concomitante, os povos colonizados conheceram uma estrutura social, político-econômico e jurídico distinta das suas, baseado no Estado Moderno. Na modernidade, as estruturas de poder contribuíram para reproduzir na periferia o esquema clássico de desenvolvimento capitalista do centro (SEGRERA, 2005). Dito isso, os problemas enfrentados nos países latino-americanos e caribenhos no contemporâneo não são puramente nacionais. Parte da geopolítica sobre a referida região reflete a construção de um discurso dominante através da condição imposta de periferias do sistema macroeconômico, sobretudo na perspectiva do Sistema-Mundo (WALLERSTEIN, 1979).

Nessa direção, a mesma tem suas bases tanto nas condições materiais de transformações históricas quanto um espaço vivido e sentido por diferentes atores sociais. A colonialidade do poder revela a inserção das Américas no mercado mundial ao engendrar novas relações materiais de produção e consumo baseadas na escravidão. $\mathrm{O}$ novo padrão de poder baseou-se na classificação racial dos sujeitos não europeus e do controle do trabalho, produção, apropriação e circulação de produtos em torno da relação capital-trabalho (QUIJANO, 2005; DUSSEL, 2005).

Os eventos históricos de dominação do capital colonial/moderno na divisão do mundo, desde colónia x metrópole até centro x periferia, consolidado pela Divisão Internacional do Trabalho, não seria possível se o universalismo europeu não subjugasse as particularidades do mundo. A totalidade ${ }^{4}$ como fenômeno da modernidade é cada vez mais desafiada pela cisão da totalidade no contemporâneo. Desde então, as periferias meridionais vivenciam processos espaciais permanentes de divisão e combinação desigual. É uma função do capitalismo moderno: estabelecer divisões e hierarquias entre os territórios para melhor dominá-los. No campo da estrutura sistêmica, o capitalismo vigente nos convence a cada dia ser o principal agente articulador dos territórios.

De fato, a América Latina representa a articulação entre as dinâmicas materiais históricos do capitalismo moderno e as constantes configurações culturais e ambientais. No entanto, por vezes alguns pesquisadores/as esquecem de sinalizar a América ser resultado de um projeto colonial e, ao cumprir a função econômica de periferia no mercado internacional, os escravizados cumpriam sua função de mercadoria. $\mathrm{O}$ espaço vivido e sentido ao longo desse território continua a ser diferenciado pela raça e etnia e mais recentemente pela classe, gênero e sexualidade.

O termo América Latina aparece em meados do século XIX como projeto ideológico em pleno governo de Napoleão III. O objetivo era criar uma unidade entre as recentes repúblicas de língua hispânica sob o controle do Estado francês para diminuir as influências do imperialismo estadunidense (FERRET; PINTO, 2011). A definição de

\footnotetext{
${ }^{4}$ A Totalidade como recurso analítico é insuficiente por ser historicamente uma prática de dominação europeia. Em contraposição, a Cisão da Totalidade propõe compreender as particularidades da unidade, do local para o global, possibilitando analisar distintos processos históricos, culturais e locais.
} 
América Latina inclina-se mais para uma concepção política e econômica fruto de processos hegemônicos, uma vez que todos os países e territórios situados ao sul dos Estados Unidos, incluindo as ilhas, compõem os países subjugados a lógica do capital representado pela Europa e mais recentemente pelo imperialismo estadunidense.

O lugar, como escala de investigação para compreender particularidades culturais não é predomínio do eurocentrismo nas periferias do capitalismo, e sim das sociedades modernas subjugadas ao domínio da colonização europeia. Consoante essa análise, a América Latina e os povos latino-americanos foram conscientemente modelados por interesses e ações alheios aos seus. As sociedades autóctones não estratificadas serviram de inspiração para o pensamento utópico europeu em nome da irrealizada utopia cristã e de uma sociedade solidária de homens livres (RIBEIRO, 1982).

Ainda hoje, o lugar como recurso analítico para observar o particular permanece como instrumento de reivindicação contra a universalização e globalização. A invenção das categorias América Latina e Caribe pelo universalismo europeu é pautado no projeto colonialista de dominação material, cultural e tecnológico, atribuindo ao território dominado à condição de "outro", "periferia", o oposto à Europa. Tal condição de periferias estabelecida pela estrutura econômica internacional ainda permanece com rebatimentos internos e externos no âmbito das relações culturais e construções sociais.

\section{Perspectiva Crítica e desprovincialização do pensamento}

No decorrer dos séculos, a colonização mostrou graus diferentes nas transformações das organizações sócioespaciais e nas atividades econômicas, possibilitando processos diferenciados. Essas transformações se distinguiram em alguns "atrasados" e outros não, em relação aos países desenvolvidos, refletindo em características do subdesenvolvimento. Além disso, as influências dos Estados Unidos e da Europa nos rumos econômicos das sociedades latino-americanas buscaram reproduzir as diversas etapas que caracterizavam as transformações sociais daqueles países, negando as singularidades de cada contexto, num movimento geopolítico arbitrário do Norte para o Sul (CARDOSO; FALETTO, 2000).

A crítica da Teoria do Discurso de Ernesto Laclau (2000) mostra a hegemonia dos valores coloniais na sobreposição das culturas dos povos originários da região. Há hegemonia quando o objetivo de um projeto particularista amplia para uma visão universalista de seus interesses. A hegemonia existe onde há desigualdade de poder, na possibilidade da existência de processos discursivos não hegemônicos. $O$ discurso dominante pressupõe uma relação de ordem, essencialmente sistematizado e universalista que parte de um discurso particular.

Há hegemonia apenas se a dicotomia universalidade/particularidade está suspensa; universalidade existe apenas encarnando e subvertendo algum objetivo particular, mas, 
de forma recíproca, nenhuma particularidade pode constituir-se como política sem se tornar o lócus de efeitos universalizantes (LACLAU, et al., 2000, p.56).

A partir de meados do século XX, surge na América Latina e Caribe organismos para promover o desenvolvimento social e econômico interno e a integração regional para encontrar alternativas de superação da Teoria da Dependência (IANNI, 1974; CARDOSO, FALETTO 2000; FURTADO, 2000; BIELSCHOWSKY, 2000), como a criação da Comunidade e Mercado Comum do Caribe em 1973, substituída pela Comunidade do Caribe, o Pacto Andino em 1969, o Mercado Comum do Sul em 1991, a Associação Latino-Americana de Integração, em 1980 e a União de Nações Americanas criada em 2008. Os últimos organismos tiveram maior preocupação no fortalecimento das relações culturais como aspecto preponderante de novas regionalizações através do processo de integração regional.

O desenvolvimento de uma unidade regional político-econômica proposta por esses organismos americanos pretendeu diminuir a crônica dependência econômica, ao desenvolver os setores produtivos internos de cada país e relações de cooperação intrarregional. Mesmo com essas configurações territoriais e os recentes avanços no setor produtivo e combate às desigualdades, ainda é comum a América Latina ser identificada com atraso tecnológico, pobreza e com dominação estrangeira, mesmo após a independência política de alguns países (ANDRADE, 1997). Essa identificação tem conexão com a permanência do papel desempenhado da América Latina na Divisão Internacional do Trabalho.

A partir da metade do século XX as Ciências Sociais na região procuraram desprovincializar pensamentos, ao passo que o elitismo das teorias europeias não dispunha de instrumentos para explicar a relevância de novos atores sociais, a exemplo de grupos indígenas e afrodescendentes no processo de democratização (COSTA, 2010). Procurou-se uma perspectiva crítica às categorias ao rever o sentido de América Latina e valorização dos conhecimentos produzidos nos países do Sul, o que possibilitou iniciar um caminho para se pensar em mudanças dos paradigmas.

$\mathrm{Na}$ busca por uma noção que possa representar a região para além das relações econômicas e construções estereotipadas, a arqueologia pré-colombiana revela que a presença africana na América ocorreu muito antes da colonização. Algumas pesquisas mostram que por meio da história oral de origem maia, os primeiros habitantes do México eram africanos (SERTIMA, 1976; NASCIMENTO, 1980; ANTA, 1981). A arqueologia pré-colombiana e as contribuições de Nascimento (1997) na interpretação das origens das populações afro-latinas destacam que alguns povos antigos do México e do Peru compartilharam a mesma palavra $R a$ para designar sol e os hieróglifos mexicanos e egípcios para essa palavra são iguais.

As evidências científicas elaboradas por esse campo científico indicam que a descolonização do pensamento requer considerar outras cosmovisões como constituintes das relações socioculturais regional. O eurocentrismo por traz do termo América Latina ainda encobre muitas experiências de populações negras e indígenas. A modernidade 
trouxe novas conformações culturais, mas o contato dos povos autóctones com outras culturas para além do Atlântico é anterior à colonização. De acordo a Grosfoguel (2008, p.43),

\begin{abstract}
Trata-se de uma perspectiva que é crítica em relação ao nacionalismo, ao colonialismo e aos fundamentalismos, quer eurocêntricos, quer do Terceiro Mundo. [...] $\mathrm{O}$ que todos os fundamentalismos têm em comum (incluindo o eurocêntrico) é a premissa de que existe apenas uma única tradição epistêmica a partir da qual pode alcançar-se a verdade e a Universalidade.
\end{abstract}

No entendimento de Grosfoguel, essa postura é essencial uma vez que as epistemologias influenciam nas relações de poder, seja no lado dominante ou subalterno. Nas últimas décadas as Ciências Sociais americanas começaram a adotar uma perspectiva crítica na construção do pensamento local ao compreender os desafios de desprovincializar os saberes hegemônicos.

\title{
Olhares sobre as Américas e o Gran Caribe
}

A porta de entrada da colonização no Caribe foi nas ilhas de Hispaniola (atualmente Haiti e República Dominicana) e Cuba e se estendeu para outras ilhas como Porto Rico (1493) e Jamaica (1494). Logo no início, as ilhas que formam o arquipélago localizado próximo ao México foram chamadas de Antilhas e tempos depois Caribe. A etimologia da palavra Caribe na qual conhecemos se prende a uma tradução espanhola ocorrida na primeira viagem à América por Cristóbal Colón em 1492. Suas anotações revelam que o Caribe é um lugar ocupado por habitantes canibales e a resistência dos ayayanos $^{5}$ a colonização espanhola resume o primeiro destino da categoria: nativo rebelde e/ou escravizado (GAZTAMBIDE, 2003).

A noção de latino-americano (incluindo o Caribe) mais difundido pelo mundo é fabricada pelo capitalismo moderno ao produzir signos negativos sobre a formação cultural em cada sociedade e legitimando relações de poder. Nas áreas meridionais do mercado internacional, a desigualdade social é mais latente, resultando num projeto de desenvolvimento incompleto, com consequências na manutenção da exploração do trabalho e na distribuição desigual de direitos sociais e cidadanias entre grupos sociais historicamente fragilizados.

Recomenda-se investigar os contextos de desigualdade na região sem dissociar das categorias raça, gênero e classe, uma vez que as estruturas de poder na região perpassam por essas categorias. No Brasil, o fim da colonização não garantiu que a população negra tivesse as mesmas condições de inclusão social e econômica em relação aos brancos. Os legados deixados pelo sistema de exploração do trabalho escravo criaram e deram continuidades as barreiras sociais entre classes, gênero e raça,

\footnotetext{
${ }^{5}$ Povos originários da ilha de Ayaya conhecida atualmente como Santa Cruz.
} 
configurando diferentes cidadanias a partir de representações sociais. A inserção do negro de modo marginalizado no mundo do trabalho continuou a consolidar os abismos sociais entre esses grupos raciais.

Até a última metade do século XIX, a economia caribenha foi caracterizada pela produção do açúcar. Antes, a região cumpriria o papel de escala de abastecimento para frotas de comércio e pirataria. $\mathrm{O}$ imperialismo norte-americano no Caribe começou com a Guerra de Secessão (1861-1865), ao marcar a transição do arranjo econômico dos Estados Unidos de agrícola em industrial. Nesse período, as transformações internas se expandiram para além de suas fronteiras e seu capital industrial já alcançava o mercado europeu. A intervenção norte-americana na guerra de independência de Cuba implicou em maiores condições para a penetração do capital norte-americano na região e domínio econômico sobre os cubanos.

O imperialismo estadunidense teve graus distintos por conta da heterogeneidade estrutural em cada país e ocorreu por meio de intervenções ideológicas como a Doutrina Monroe, União Pan-americana e a Política da Boa vizinhança, a partir da ideia de "binômio", como combinação entre políticas de integração com doutrinas de seguridade (NOVION, 2014). Segundo Azevedo e Herbold (1986), a penetração da economia capitalista na República Dominicana foi favorecida por latifúndios e elite oligárquica. Diferente no Haiti, a condição de infraestrutura não o favorecia: mercado interno caracterizado pela economia mercantil e elevada quantidade de arrendatários de terras estatais e particulares.

O período pós-Segunda Guerra caracterizou a maioria dos países americanos na busca por autonomia política e solução dos problemas sociais. A influência de capitais norte-americanos e a progressiva redução dos interesses europeus levaram à expansão do imperialismo estadunidense. Esse contexto desencadeou processos políticos particulares, insatisfações por parte de movimentos sociais e novos conflitos urbanos, além de aprofundar as desigualdades.

Enquanto Adam Smith em "Riqueza das Nações" (1982) defendia o liberalismo econômico, a partir da hegemonia do centro sobre as periferias, o Estruturalismo Latinoamericano pensava as relações econômicas do sistema capitalista a partir da condição imposta de periferia, evidenciando que o liberalismo produz desigualdades e dependência. Pensar a região a partir de sua própria realidade, desafios econômicos e diversidades culturais orientou as políticas desenvolvimentistas na busca de superação da condição de periferia do capitalismo moderno.

Contrapondo as políticas liberais e forças imperialistas na região, o pensamento antillanista ${ }^{6}$ é um caso representativo na compreensão de outras configurações políticas e ideológicas. O movimento antillano surge num contexto de lutas independentistas e anticolonialistas em Porto Rico e Cuba, no final do século XIX, exprime o sentimento de união das Antilhas e tem como inspiração o pensamento de José Martí. As pautas

\footnotetext{
${ }^{6}$ Outras figuras simbolizam o pensamento antillanista como o dominicano Gregorio Luperón e os portoriquenhos Ramón Emeterio Betances e Eugenio María do Hostos.
} 
giravam em torno do anti-imperialismo, reconhecimento das identidades locais e independência.

Cree el aldeano vanidoso que el mundo entero es su aldea, y con tal
que él quede de alcalde, o le mortifique al rival que le quitó la
novia, o le crezcan en la alcancía los ahorros, ya da por bueno el
orden universal [...]. Lo que quede de aldea en América ha de
despertar. Estos tiempos no son para acostarse con el pañuelo en la
cabeza, sino con las armas en la almohada, como los varones de
Juan de Castellanos: las armas del juicio, que vencen a las otras.
Trincheras de ideas valen más que trincheras de piedra (MARTÍ,
1981, p. 01).

$\mathrm{O}$ antilhanismo propunha a construção de uma unidade latino-americana. $\mathrm{O}$ pensamento de Simón Bolívar contribuiu significativamente para a construção de uma unidade regional, ao considerar a participação das massas populares nas lutas por autonomias e soberanias. O caráter anticolonial, de identidades e liberdades que orientou outros processos como a Revolução Cubana (1953-1959) procurou construir novas histórias para que o horizonte futuro tivesse um significado cultural e político próprio. A criação do Partido Revolucionário Cubano, em 1892, por Martí, já indicava um projeto político nacional e regional por independência.

O viés "latino" da região muitas vezes se apresenta reducionista do ponto de vista de construção da unidade regional proposto por Simón Bolívar e outros. Em geral e, especificamente no Brasil, não é fácil encontrar estudos sobre a República da Guiana, Suriname e a Guiana Francesa. Localizados no norte-sul do continente, esses países foram colonizados por ingleses, holandeses e franceses, respectivamente. Inclusive, a Guiana Francesa, até então, é um território sobre o domínio colonial francês.

As idiossincrasias nesses territórios, assim como as experiências negras, indígenas e de imigrantes ainda é algo quase desconhecido para os estudos brasileiros. Cavlak (2015) entende que apesar das Guianas estarem situas na América do Sul, foram incorporadas à produção historiográfica do Caribe pelas peculiaridades de sua colonização e, mesmo assim, de modo marginal por conta de processos históricos nacionais no Caribe que ganharam mais relevância, a exemplo da Jamaica, Haiti, Cuba e República Dominicana.

Apesar de a colonização ter provocado diferentes configurações socioculturais ao longo das Américas, a dimensão puramente econômica da escravidão e pósescravidão e a implantação arbitrária da língua dos dominadores não são suficientes para determinar uma ideia de unidade regional. Ao buscar outros horizontes epistêmicos, acredita-se que as experiências negras e indígenas, sobretudo, criaram conexões de sentidos entre os povos subjugados, além das semelhanças e diferenças entre povos e territórios. A língua inglesa, hispânica e portuguesa que predominam em toda a região não pode ser considera um aspecto fim para o sentido de unidade. Se for, essa lógica é minimamente restritiva, excludente e contraditória porque exclui o Suriname e as Guianas da perspectiva "latina". 
O capitalismo moderno edificou a região latino-americana e caribenha como uma construção social do eurocentrismo colonial. Nesses termos, a noção de América e Latina como representação de uma unidade cultural regional não deve ser considerada, pelo menos em primeira instância. Isso porque é/são termo(s) eurocêntricos e, na crítica aos axiomas coloniais e imperialistas estão submetidos à lógica do mercado internacional. A filosofia do materialismo histórico nos ajuda a compreender a região e, em especial a América Latina "[...] uma resposta local aos processos capitalistas" (GILBERT, 1988, p.209). Consoante com Gilbert, Bonfim (1997, p.32) compreender a seguinte questão:

Expressão de tanto uso, essa América Latina deve servir,
sensatamente, para designação geográfica - do grupo de nações
formadas por ibéricos, num regime colonial de subordinação e
dependência imediata, e que logo se degradou em parasitismo,
despótico, antiprogressista. No mais, é designação nula, própria
somente para a tecnologia fútil dos que, aceitando a divisão fácil
do Ocidente em - latinos, germânicos, eslavos... voltados para este
lado, concluem que deve haver uma América Latina para
contrapor-se à América inglesa.

A ideia de América Latina e Caribe através da condição de periferia do sistema internacional tem rebatimentos internos e externos no âmbito das relações culturais e construções sociais. Mello (2003) ao analisar a região a partir de discursos brasileiros por meio de jornais, estudantes de escola pública e revistas de turismo identifica como fio condutor entre esses recortes investigados o estereótipo sobre o Gran Caribe. A pesquisa mostrou que a região é vista como um produto de um mercado turístico, ligado à prostituição, permissividades, sensualidade, racialização do trabalho, imagem de uma "terra sem lei", festas, danças, dentre outras características que formam um conjunto de representações negativas.

Os imaginários sociais do ser latino-americano e caribenho difundidos pelo mundo e replicado em partes, nas Américas, elaborados pelas ideologias excludentes, delimitam a própria percepção das identidades dos sujeitos locais, uma ideia voltada para as dimensões de subordinação econômica e hierarquia sociocultural, sobretudo. Há situações que mostram como constantes tentativas de hierarquização social estão arraigadas nos valores das sociedades ocidentalizadas.

Atualmente, por não haver definição exata de Caribe e América Latina, alguns/as pesquisadores/as latino-americanos/as como Rojo-Benítez (2004) e Ester Ceceña (2000) propõem uma regionalização ou sentidos que considerem a definição histórica, econômico-cultural e político, como Caribe Geopolítico, Gran Caribe ou Cuenca del Caribe, Caribe Insular ou Étno-Histórico, Caribe Afro-América Central ou Caribe Cultural.

A definição de Gran Caribe (figura 1) por alguns autores, a exemplo de Mayor (1980), compreende a "América das plantações" ao considerar parte do Norte e Nordeste brasileiro, Centro-América, as Ilhas e a região do Sul dos Estados Unidos. Essas 
regionalizações caracterizadas pela centralidade das ações dos sujeitos negam a dimensão exclusivamente econômica e propõe regionalidades a partir das relações culturais e étnico-raciais elaboradas por populações negras, indígenas e outras minorias.

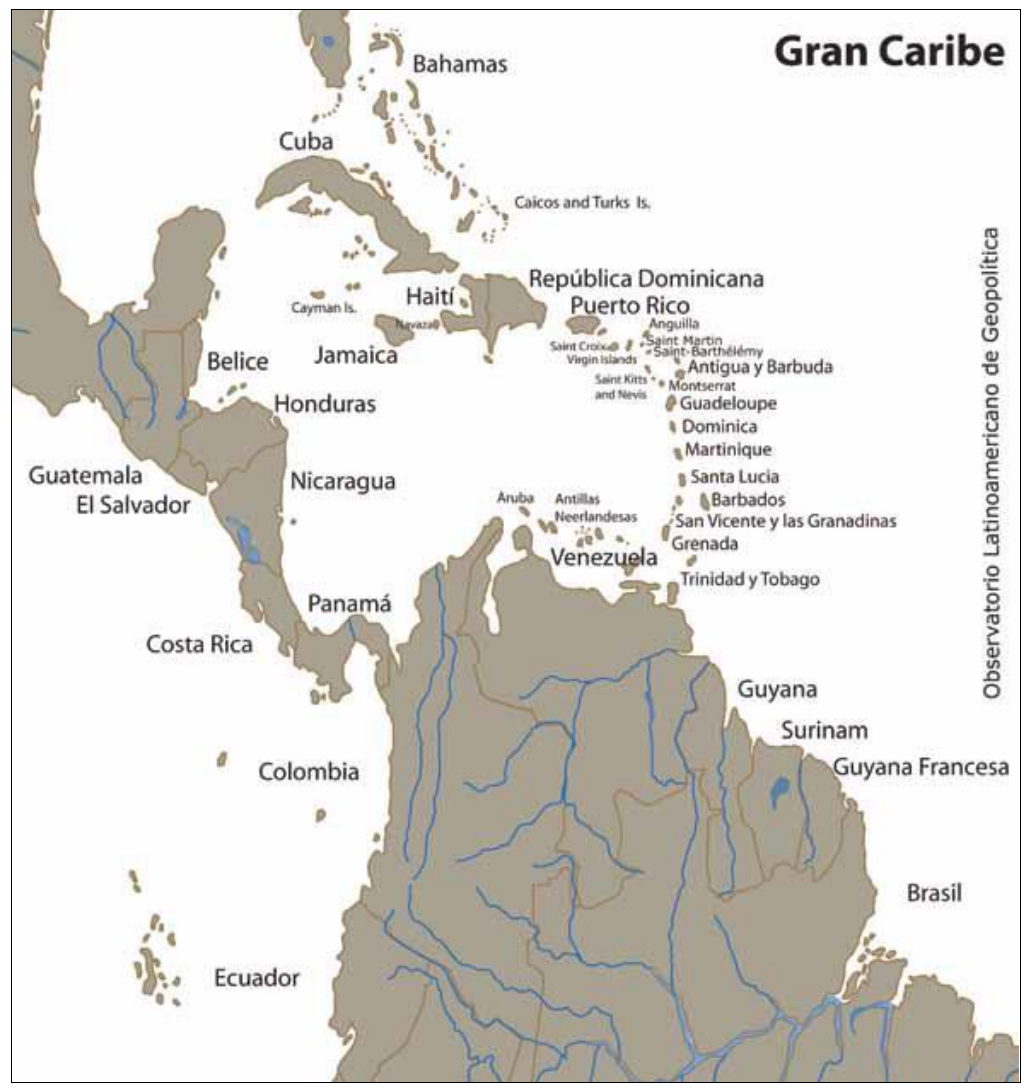

Figura 01: A região do Gran Caribe

Fonte: Ceceña, et al. (2000).

A categoria Gran Caribe parte de um lugar de atuação específica na produção do conhecimento latino-americano e caribenho legitimada por um campo epistêmico local ao ampliar os horizontes outras epistemologias e produção do conhecimento intrarregional.

Em primer lugar, entiendo ló caribeño, em su dimensión sociocultural, como producto resultante de la plantación esclavista, ya corresponda ésta a las Antillas o a su periferia continental; esto es, escrita dentro de sociedades esclavistas, se extiende a lo largo del siglo XIX desde Cuba hasta el Brasil (ROJO-BENÍTEZ, 2004, p.14-15). 
A definição de Gran Caribe proposta pelo autor considera processos sociais, históricos e culturais singularizados pela escravidão, ao resultarem na combinação de novos elementos culturais e o sistema de plantation. Acredita-se na inviabilidade de compreender o Gran Caribe sem considerar as conexões de sentidos entre as experiências das populações negras e indígenas nas dinâmicas dos territórios e configurações culturais. Certamente a economia da escravidão e seus legados compõem parte do sentido de Gran Caribe. No entanto, tal perspectiva leva em consideração o conteúdo histórico de processos de luta antirracista e por independência, na possibilidade de pensar a região sobre outras bases de regionalização.

\section{Considerações}

$\mathrm{O}$ artigo refletiu acerca dos principais pressupostos que contribuíram para a formação da América Latina e Caribe. Esse universo relacional possibilitou verificar que a noção de latino-americano e caribenho representa um projeto colonial do universalismo europeu e mais atualmente influenciado por processos imperialistas.

As contradições estabelecidas pela modernidade determinam, em primeira instância, a funcionalidade macroeconômica da América Latina e Caribe como uma região periférica do sistema internacional. No entanto, somente essa dimensão econômica não caracteriza esse território. Com isso, seria necessário pensar outras regionalizações possíveis para explicar distintos processos históricos e sociais, assim como diferentes realidades culturais e políticas não essencializada.

Apesar dos esforços da Geografia e das Ciências Sociais americanas nas últimas décadas na produção do conhecimento crítico ao eurocentrismo, a predominância da perspectiva regional a partir de América Latina, incluindo o Caribe, ainda reproduz valores hegemônicos, tendendo a silenciar experiências de populações negras e indígenas. Apesar das diferentes interpretações sobre a região, nenhuma categorização é suficiente para explicar sua complexidade. As interpretações desenvolvidas sobre o continente americano são representações ideológicas que criam espaços de diálogo dentro da região, com a Europa e com o Sul. Num olhar epistêmico, não-reducionista, é necessária pôr em evidencia uma perspectiva de análise que dialogue com outras categorias e que melhor se adeque a abordagem e metodologia da pesquisa acerca da região, uma vez que há várias Américas.

O uso da categoria Gran Caribe, representativo de parte das dinâmicas histórico-culturais ainda em curso, estabelece conexões com outras dimensões de investigação no campo da política, da cultura, histórico e social. Trata-se de um caminho relevante para descortinar novas perspectivas regionais.

\section{Referências Bibliográficas}

ANDRADE, M. C. de. Brasil e a América Latina. 1997. 
ANTA, D. C. Civilisation ou barbárie. Paris: Présence africaine, 1981.

AZEVEDO, E. R.; HERBOLD, H. Caribe: o paraíso submetido. São Paulo: Editora Brasiliense, 1986.

BOMFIM, M. O Brasil na América: caracterização da formação brasileira. $2^{\mathrm{a}}$ edição. Rio de Janeiro: Topbooks, 1997.

CABRERA, O. Entre a invisibilidade e a cor do medo: literatura e escravidão no Brasil e em Cuba. In: ALMEIDA, J.; CABRERA, O. (Orgs.). Caribe, sintonias e dissonâncias. Goiânia: Centro de Estudos do Caribe no Brasil, 2004.

CARDOSO, F.H. e FALETTO, E.. Dependência e Desenvolvimento na América Latina. In: BIELSCHOWSKY, R. (Org.). Cinqüenta anos de pensamento na CEPAL. Ed. Record. SP/SP (2000), p. 497-519.

CAVLAK, I. O Extremo Norte da América do Sul: A Guiana Inglesa e o Suriname no século XIX. FACES DA HISTÓRIA, Assis-SP, v.2, nº1, p. 96-114, jan.-jun., 2015. Disponível em: <http://seer.assis.unesp.br/index.php/facesdahistoria/article/download /194/187/>. Acesso em: 12 jan. 2019.

CECEÑA, A. E. et al. (Orgs.). El Gran Caribe. Umbral de la geopolítica mundial. Quito, Equador: Edición: Observatório Latinoamericano de Geopolítica, 2010.

CHEPTULIN, A. A dialética materialista: categorias e leis da dialética. São Paulo: Alfa \& Omega, 1982.

CLAVAL, P. The region as a geographical, economic and cultural concept. International Social Science Journal, Oxford, v. 39, n. 2, 1987, p. 159-172.

CLAVAL, P. L'Évolution de la géographie humaine. Paris: Les Belles Lettres, 1974.

COSTA, S. Teoria por Adição. In: C.B. Martins, H. H. de Souza Martins (Orgs.). Horizontes Sociológicos. São Paulo: ANPOCS, 2010.

CORRÊA, R. L. O espaço urbano. $3^{\text {a }}$ ed. São Paulo: Ática, 1995.

CORRÊA, R. L. Geografia: conceitos e temas. Rio de Janeiro, Bertrand Brasil, 2003.

DUARTE, A. C. Regionalização: considerações metodológicas. Boletim de Geografia Teorética, Rio Claro, v. 10, n. 20, 1980, p. 5-32.

DUSSEL, E. Europa, modernidade e eurocentrismo. In: LANDER, E. (Org.). A colonialidade do saber: eurocentrismo e Ciências Sociais. Perspectivas latinoamericanas. Colección Sur-Sur, CLACSO, Buenos Aires, Septiembre, 2005.

FERRET, R. L; PINTO, S. R. América Latina: da construção do nome à consolidação da ideia. Topoi, Rio de Janeiro, vol.12, nº 23. jul./dez. 2011. Disponível em:

http://www.revistatopoi.org/numeros_anteriores/topoi23/topoi23_a02_america_latina.pd f. Acesso em: 17 maio 2018. 
FREEDEN, M. Ideologies and Political Theory: A Conpectual Approach. Oxford, UK: Oxford University Press, 1988.

FURTADO, C. Desenvolvimento e Subdesenvolvimento. In: BIELSCHOWSKY, R. (Org.). Cinqüenta anos de pensamento na CEPAL, v 1. São Paulo: Ed. Record, 2000

GAZTAMBIDE. A. La invención del Caribe a partir de 1898 (Las definiciones del Caribe, revisitados), 2003. Disponível em: http://www2.scielo.org.ve/scielo.php?script=sci_arttext\&pid=S079829682003000200004\&lng=es\&nrm=i. Acesso em: 20 maio, 2018.

GILBERT, A. The New Regional Geography in English and French-speaking Countries. Progress in Human Geography, 12(2), p. 208-228,1988. Disponível em: https://journals.sagepub.com/doi/10.1177/030913258801200203. Acesso em 12 de fevereiro de 2020.

GROSFOGUEL, R. Developmentalism, modernity and dependency theory in Latin America. In: MARANÃ, M; DUSSEL, E; JÁUREGUI, Carlos (Eds.) Coloniality at large. Latin America and the postcolonial debate. Duke University Press, 2008.

HAESBAERT, R. Região, Regionalização e regionalidade: questões contemporâneas. ANTARES, Rio de Janeiro, $\mathrm{n}^{\mathrm{o}}$ 3, jan./jun., 2010. Disponível em: https://edisciplinas.usp.br/pluginfile.php/4553781/mod_resource/content/1/3.haesbaert.p df. Acesso em 24 de fev. de 2020.

HERBERTSON, A. J. The major natural regions: an essay in systematic geography. The Geographical Journal, London, v. 25, n. 3, 1905, p. 300-312. Disponível em: https://www.people.iup.edu/rhoch/ClassPages/Thought\%20and\%20Philosophy/Readings /Week2/Herbertson.pdf. Acesso em 24 de fev. de 2020.

HARVEY, D. A produção capitalista do espaço. São Paulo: Annablume, 2005.

IANNI, O. Imperialismo na América Latina. Rio de Janeiro: Civilização Brasileira, 1974.

LACLAU, E.; BUTLER, J; ZIZEK, S. Contingency, Hegemon, Universality: Contemporary Dialogues on the Left. London, Verso, 2000.

LACLAU, E.; MOUFFE, C. Hegemonía y estrategia socialista. Hacia una radicalización de la democracia. London, Verso, 1985. Disponível em:

http://perio.unlp.edu.ar/catedras/system/files/laclau_hegemonia_estrategia_socialista_3.p df. Acesso em: 07 jun. 2018.

LACOSTE, Y. A Geografia: isso serve, em primeiro lugar, para fazer a guerra. Campinas: Papirus, 1989.

LENCIONI, S. Região e Geografia. São Paulo: Edusp, 2003. 
MAYOR, F. Historia General del Caribe. 1980. Disponível em: http://www.unesco.org/culture/caribbean/pdf/ghc_preface_es.pdf. Acesso em: 12 set. 2018.

MARTÍ, J. Nuestra América. Disponível em: http://bibliotecavirtual.clacso.org.ar/ar/libros/osal/osal27/14Marti.pdf. Acesso em: 19 out. 2018.

MELLO, M. T. N. Santa Maria, Pinta e Nina: a redescoberta dos Caribes em espaços discursivos brasileiros. In: ALMEIDA, Jaime. et al. Cenários Caribenhos. Brasília: Paralelo 15, 2003.

NASCIMENTO, A. Aspectos da experiência afro-brasileira. In: Thoth. Informe de distribuição restrita do senador Abdias Nascimento. no 3, p. 167-184, 1997. Disponível em:http://www2.senado.leg.br/bdsf/bitstream/handle/id/502815/000526595_3.pdf?seque nce $\% 20=3$. Acesso em: 10 abr. 2018.

NASCIMENTO, E. L. Pan-Africanismo na América do Sul: emergência de uma rebelião negra. Brasília: Vozes, 1980.

NOVION, J. de. Hegemonia, integración y Seguridad en las Américas. 2014. Disponível em:

http://portal.anpocs.org/portal/index.php?option=com_docman\&task=doc_view\&gid=90 75\&Itemid=456. Acesso em: 10 abr. 2018.

PRADO, E. A ilusão americana. 4ª ed. São Paulo: Magalhães, 1917.

QUIJANO, A. Colonialidad del poder, eurocentrismo y América Latina. In: LANDER, E. (Org.). A colonialidade do saber: eurocentrismo e ciências sociais. Perspectivas latinoamericanas. Colección Sur-Sur, CLACSO, Ciudad Autónoma de Buenos Aires, Argentina. Setembro, 2005. Disponível em: http://biblioteca.clacso.edu.ar/ar/libros/lander/pt/lander.html. Acesso em: 25 fev. 2019, p. 96-107.

RIBEIRO, D. La nación latinoamericana. In: 30 Años de Nueva Sociedad. Nueva Sociedad, $\quad \mathrm{n}^{\circ} 180-181$ Jul-Ago/Sep-Oct., 1982. Disponível em: https://nuso.org/media/articles/downloads/3062_1.pdf. Acesso em 24 de fev. de 2020.

ROJO-BENÍTEZ, A. El Caribe a Conexão Afro-Atlântica. In: ALMEIDA, J.; CABRERA, O. (Orgs.). Caribe, sintonias e dissonâncias. Goiânia: centro de estudos do Caribe no Brasil, 2004.

SANTOS, M. A natureza do espaço: técnica e tempo, razão e emoção. $4^{\mathrm{a}}$ ed. São Paulo: Edusp, 2004.

SANTOS, M. Espaço e método. São Paulo: Nobel, 1985.

SANTOS, M. O Trabalho do Geógrafo no Terceiro Mundo. 2. ed. São Paulo: Hucitec, 1991. 
SREGRERA, F. L. Abrir, "impensar" e redimensionar as ciências sociais na América Latina e Caribe. É possível uma ciência social não eurocêntrica em nossa região? 2005. Disponível em:

http://biblioteca.clacso.edu.ar/ar/libros/lander/pt/lander.html. Acesso em 11 de fev. de 2020.

SERTIMA, I. V. Eles vieram antes de Colombo: a presença africana na América antiga, 1976.

SORRE, MAX. A Geografia Humana (Introdução). GEOgraphia. Ano V, No 10, 2003. Disponível em: http://periodicos.uff.br/geographia/article/download/13461/8661. Acesso em 24 de fev. de 2020.

SMITH, A. A Riqueza das Nações: investigação sobre sua natureza e suas causas. São Paulo: Abril Cultural, 1982.

WALLERSTEIN, I. O universalismo europeu: a retórica do poder. Tradução: Beatriz Medina. São Paulo: Boitempo, 2007.

WALLERSTEIN, I. The modern world-system: capitalist agriculture and the origins of the european world-economy in the sixteenth century. New York/London: Academic Press, 1979.

Adalberto de Salles-Lima

Licenciado em Geografia pela Universidade do Estado da Bahia. Mestre e doutorando em Ciências Sociais pelo Programa de Pós-Graduação em Estudos Comparados sobre as Américas do Departamento de Estudos Latino-Americanos (ELA), vinculada ao Instituto de Ciências Sociais da Universidade de Brasília (UnB). Integrante do Grupo de Pesquisa Recôncavo: Território, Cultura, Memória e Ambiente - Universidade do Estado da Bahia. Integra o Núcleo de Estudos AfroBrasileiros - NEAB/UnB e também o Grupo de Pesquisa CASCA - Coletivo de Antropologia e Saúde Coletiva/UnB.

UnB - Brasília, DF, 70910-900

sallesvitoria@hotmail.com

Recebido para publicação em maio de 2019 Aprovado para publicação em dezembro de 2019 